Original Research Article

\title{
A study on outcome of various K-wire fixations in paediatric supracondylar humerus fractures
}

\author{
Shalin Bharat Shah, Kushal Nikhil Parikh*, Pradipkumar Ishvarbhai Paraliya
}

Department of Orthopaedics, SMIMER Hospital, Surat, Gujarat, India

Received: 20 July 2020

Revised: 04 August 2020

Accepted: 05 August 2020

\author{
*Correspondence: \\ Dr. Kushal Nikhil Parikh, \\ E-mail: kushalparikh@yahoo.com
}

Copyright: (c) the author(s), publisher and licensee Medip Academy. This is an open-access article distributed under the terms of the Creative Commons Attribution Non-Commercial License, which permits unrestricted non-commercial use, distribution, and reproduction in any medium, provided the original work is properly cited.

\begin{abstract}
Background: The ideal pin geometry for treatment of paediatric supracondylar humerus fracture is still debated. Various studies have been carried out comparing medial-lateral pinning (MLP) and lateral only pinning (LOP), but none have compared all three individually i.e. MLP, lateral divergent pinning and Lateral Trans olecranon fossa four cortex purchase pinning (TOF-FCP). This study aims to compare the cosmetic and functional outcome of these three pinning methods.

Methods: 54 children with supracondylar humerus (Gartland type 2 or 3) meeting inclusion criteria were treated operatively and followed up till 6 months postoperatively. At 6 months the cosmetic and functional outcomes were assessed using the modified Flynn criteria.

Results: All fractures united within 3 to 6 weeks duration. The mean duration of fracture union was 4.05 weeks. Functional outcome was satisfactory (i.e. excellent or good) at 6 months according to Flynn criteria in $95 \%$ of cases in cross pinning, $100 \%$ cases in TOF-FCP construct and $89 \%$ cases in lateral entry divergent pinning. cosmetic outcome was satisfactory (i.e. excellent or good) at 6 months according to Flynn criteria in $95 \%$ of cases in cross pinning, 100\% cases in TOF-FCP construct and $89 \%$ cases in lateral entry divergent.

Conclusions: Functional and cosmetic outcome of all three pinning geometries after operative intervention of paediatric supracondylar humerus fracture is similar in expert hands. The incidence of complications with TOF-FCP construct is less amongst the lateral only pinning.
\end{abstract}

Keywords: SCHF, TOF-FCP, Medial-lateral pinning, Lateral only pinning

\section{INTRODUCTION}

Supracondylar humerus fracture is the most common elbow fracture in children. They account for $55 \%$ to $70 \%$ of all elbow fractures and are seen most frequently in children between the ages of 3 and 10 years. ${ }^{1}$ The chances of residual deformity and that for rare but devastating neurovascular complications make supracondylar humerus fractures a dreaded injury. Over time, we have advanced from the conservative approach to an operative approach with closed reduction percutaneous pinning as the acceptable mode of treatment.
The current standard treatment for displaced supracondylar humerus fracture is closed reduction and percutaneous pinning. This method has consistently given excellent results reported by various authors. However, controversy still exists regarding which pin fixation is the best in terms of stability and iatrogenic ulnar nerve injury.

Medial and lateral pin fixation has been presumed to be more stable, however it has the risk of iatrogenic ulnar nerve injury. Lateral only pinning is riddled with issue of lesser torsional stability but avoiding neurological complications. Recently 'trans-olecranon fossa-four 
cortex purchase (TOF-FCP)' pin fixation technique has reports of having better torsional stability than conventional LOP and retaining its fewer complications. ${ }^{2}$ But it affects mobility at elbow with early stiffness. Therefore, we conducted this prospective study to compare the outcome of all the three constructs for cosmetic and functional outcomes and complications comparison.

\section{METHODS}

A prospective study which was carried out over a period of 18 months from January 2018 to July 2019 at Surat Municipal Institute of Medical Education and Research, Surat, Gujarat, India. The study protocol was approved by the ethics committee of our institution. Gartland classification was used to classify fractures. ${ }^{3}$ All displaced supracondylar humerus fracture (Gartland type II or III fracture) of children aged less than 16 years were included. Only fresh ( $<7$ days) fractures were included. Children with other ipsilateral limb fractures, Gartland type 1 fracture and with preoperative distal neuro-vascular deficits were excluded.

On operation table closed reduction was done under anaesthesia. After achieving an acceptable reduction confirmation under IITV, the corresponding pinning was carried out. Three consultants with adequate experience, each operating with one fixation technique carried out the surgery, sampling technique being purposive sampling.

Crossed pin configuration was carried out according to the mini-open technique described by Green et al. ${ }^{4}$ In lateral only pinning, divergent pinning was carried out according to the technique explained by Aroson and Prager in their study, TOF-FCP pinning was done according to the technique described by Kasirajan et al in their study. ${ }^{5}$ In TOF-FCP construct the entry of the $\mathrm{K}$-wire is at the capitellum, being the first cortex the next two being those of the olecranon fossa and fourth, the medial column. The pin size used was $1.5 \mathrm{~mm}$ in younger children $(<20 \mathrm{~kg}$ weight) and $2 \mathrm{~mm}$ in older children (>20 kg weight).

Betadine soaked gauze piece were put around each pin and an above elbow slab was applied. A single shot of injectable antibiotic was given intra-operatively with oral antibiotics continued post-operatively only in cases with post-operative pin tract infection.

All cases were followed up at 3 weeks and thereafter weekly till clinical evidence of absent fracture site tenderness and radiological reporting of evidence of union. On confirmation of both, the pins were removed, and gradual mobilization was started as tolerated. After that they were followed up at 3 months and 6 months. The 6 months assessment were used to assess and compare the cosmetic and functional outcomes. The functional and cosmetic outcome were graded according to the modified Flynn criteria. ${ }^{6}$ Analysis was done of the qualitative data using cross tab analysis.

\section{RESULTS}

Our study was carried out amongst paediatric patients with supracondylar humerus fracture, wherein a total of 54 displaced supracondylar humerus (Gartland type 2 and 3) fractures in children were studied. Age distribution wise, $22(40.7 \%)$ children were under 6 years, $26(48.1 \%)$ children were between 6 to 10 years and $6(11.1 \%)$ children were above 10 years. Mean age was 6 years. (range from 2 to 12 years). Sex distribution wise, 31 were males $(57.4 \%)$ and 23 children were females (42.6\%), showing near equal distribution. Out of 54, in 19 cases cross pinning was done and in 35 cases lateral pinning was done. Out of 35 lateral pinned cases 17 were 'trans olecranon fossa four cortex purchase' (TOF-FCP) and 18 were divergent lateral entry. All patients having extension type injuries were included in our study.

Of the total of 54, 15 (27.8\%) were Gartland type 2 and 33 were Gartland type 3 fractures. Twenty-five (53.7\%) were type $3 \mathrm{a}$ and $8(18.5 \%)$ were type $3 \mathrm{~b}$. Distribution amongst the pinning method of various fracture types was random and found to be equivocal. Out of 54 cases, 43 (79.6\%) cases were operated within 1 day and the rest $11(20.4 \%)$ cases were operated after 24 hours and within 1 week due to delayed presentation ( 3 cases by cross pinning and 8 cases by lateral pinning: 5 TOF-FCP; 3 divergent). Mean duration between injury and surgery was 1.5 days.

Out of 19 cross pinned cases, according to Flynn criteria showed excellent functional outcome in 15 cases, good in 3 case and fair in 1 case. The cosmetic outcome according to Flynn criteria showed excellent outcome in 15 cases, good in 3 case and fair in 1 case (Table 1). However, the cosmetic outcome and functional outcome is not correlated.

Table 1: Frequency tabulation of cosmetic and functional outcome of cross pinned cases.

\begin{tabular}{|lllllll|}
\hline \multirow{2}{*}{$\begin{array}{l}\text { Fracture } \\
\text { type }\end{array}$} & \multicolumn{2}{l}{$\begin{array}{l}\text { Cosmetic } \\
\text { outcome }\end{array}$} & \multicolumn{4}{c|}{$\begin{array}{l}\text { Functional } \\
\text { outcome }\end{array}$} \\
\cline { 2 - 8 } & E & G & F & E & G & F \\
\hline 2 & 6 & 0 & 0 & 6 & 0 & 0 \\
\hline 3A & 7 & 1 & 1 & 7 & 2 & 0 \\
\hline 3B & 2 & 2 & 0 & 2 & 1 & 1 \\
\hline
\end{tabular}

E= Excellent; $\mathrm{G}=$ Good; F= Fair.

The average time to clinico-radiological union in this fixation was 3.8 weeks. Pin tract infection of very mild nature was detected in 4 patients. In one patient one of the wires backed out due to loss of cortical purchase leading to secondary displacement. It was revised with close reduction and percutaneous pinning. The functional outcome was fair in that case. $4(21.1 \%)$ cases showed mild displacement as per Skaggs criteria on assessment of follow up Baumann's angle shows radiographs and clinical photograph of a 7 years old male child operated with medial lateral pinning and excellent radiological and functional outcome (Figure 1). 


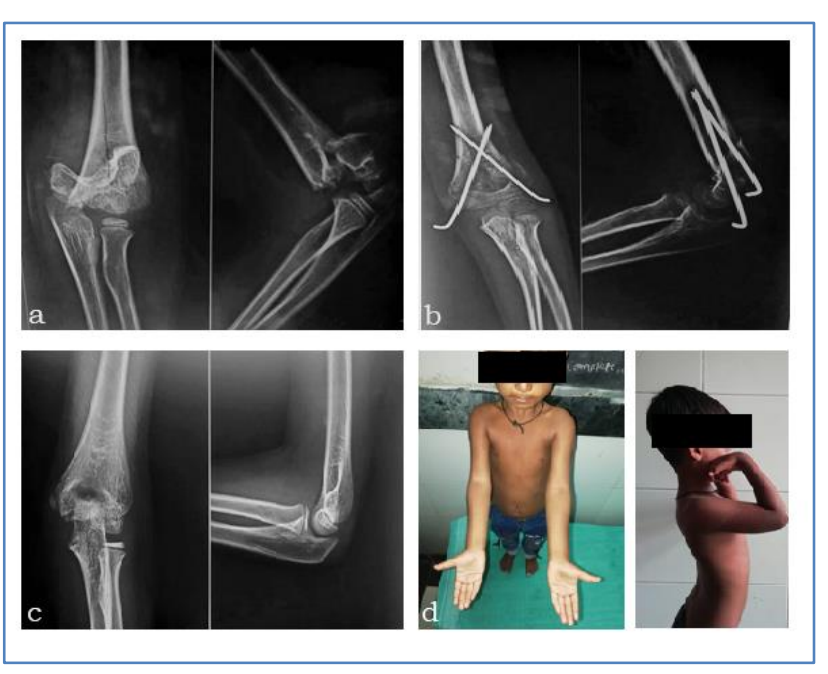

Figure 1: (a) Pre-operative radiograph of mediallateral pinning case, (b) post-operative radiograph of medial-lateral pinning case, (c) follow-up radiograph of medial-lateral pinning case and (d) clinical photograph of medial-lateral pinning case.

Out of 17 TOF-FCP cases, the functional outcome according to Flynn criteria showed excellent outcome in 12 cases and good in 5 cases. The cosmetic outcome according to Flynn criteria showed excellent outcome in 14 cases, good in 3 cases (Table 2).

Table 2: Frequency tabulation of cosmetic and functional outcome of TOF-FCP cases.

\begin{tabular}{|lllllll|}
\hline $\begin{array}{l}\text { Fracture } \\
\text { type }\end{array}$ & \multicolumn{2}{l}{$\begin{array}{l}\text { Cosmetic } \\
\text { outcome }\end{array}$} & \multicolumn{4}{c|}{$\begin{array}{l}\text { Functional } \\
\text { outcome }\end{array}$} \\
\hline $\mathbf{2}$ & E & G & F & E & G & F \\
\hline $\mathbf{2}$ & 3 & 1 & 0 & 3 & 1 & 0 \\
\hline 3A & 7 & 3 & 0 & 8 & 2 & 0 \\
\hline 3B & 2 & 1 & 0 & 3 & 0 & 0 \\
\hline
\end{tabular}

$\mathrm{E}=$ Excellent; $\mathrm{G}=$ Good; $\mathrm{F}=$ Fair.

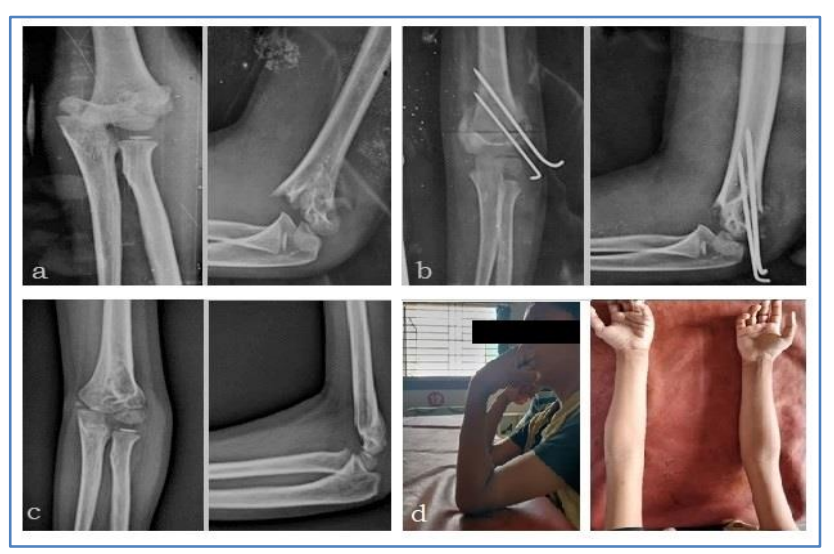

Figure 2: (a) Pre-operative radiograph of TOF-FCP pinning case, (b) post-operative radiograph of TOFFCP pinning case, (c) follow-up radiograph of TOFFCP pinning case and (d) clinical photograph of TOFFCP pinning case.
The average time to clinico-radiological union in this fixation was four weeks. Pin tract infection of very mild nature was detected in 4 patients. Four cases showed mild displacement as per Skaggs criteria on assessment of follow up Baumann's angle without secondary displacement shows radiographs and clinical photograph of an 8 years old child operated with TOF-FCP pinning with excellent radiological and functional outcome (Figure 2).

Out of 18 laterals only pinned cases the functional outcome according to Flynn criteria showed excellent outcome in 12 cases and good in 2 cases and fair in 2 cases. The cosmetic outcome according to Flynn criteria showed excellent outcome in 14 cases, good in 3 cases and fair in 1 case (Table 3 ).

Table 3: Frequency tabulation of cosmetic and functional outcome of lateral only pinned cases.

\begin{tabular}{|lllllll|}
\hline $\begin{array}{l}\text { Fracture } \\
\text { type }\end{array}$ & \multicolumn{2}{l}{$\begin{array}{l}\text { Cosmetic } \\
\text { outcome }\end{array}$} & \multicolumn{4}{c|}{$\begin{array}{l}\text { Functional } \\
\text { outcome }\end{array}$} \\
\hline $\mathbf{2}$ & E & G & F & E & G & F \\
\hline $\mathbf{2}$ & 3 & 1 & 0 & 3 & 1 & 0 \\
\hline 3A & 8 & 1 & 1 & 8 & 1 & 1 \\
\hline 3B & 2 & 0 & 1 & 2 & 1 & 0 \\
\hline
\end{tabular}

$\mathrm{E}=$ Excellent; $\mathrm{G}=$ Good; $\mathrm{F}=$ Fair.

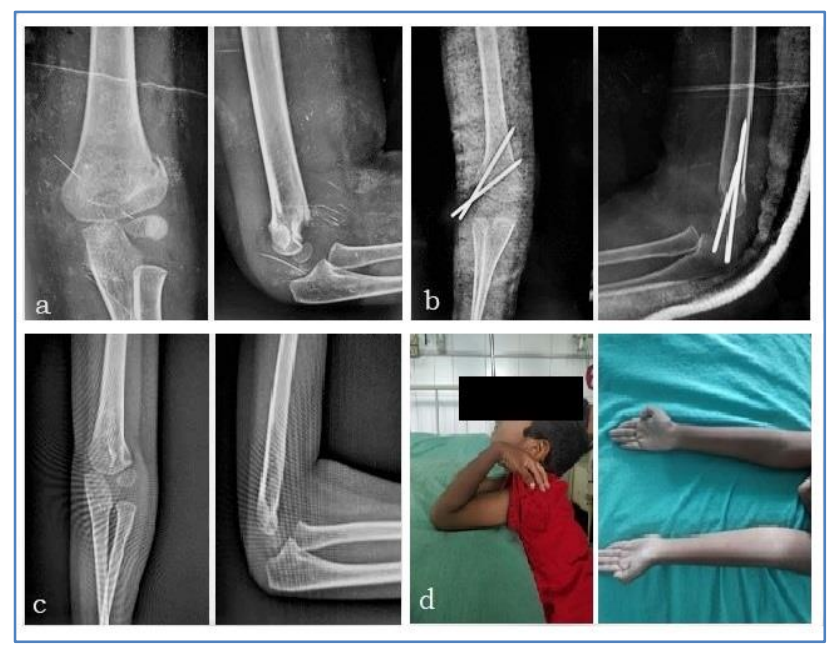

Figure 3: (a) Pre-operative radiograph of lateral only pinning case, (b) post-operative radiograph of lateral only pinning case, (c) follow-up radiograph of lateral only pinning case and (d) clinical photograph of lateral only pinning case.

The average time to clinico-radiological union in this fixation was 4.2 weeks. Pin tract infection of very mild nature was detected in 6 patients, in one of those case it was the cause of elbow stiffness in the early follow up. In one patient, both the wires were crossing too close to fracture site leading to secondary displacement and in one patient one of the wires became unicortical postoperatively leading to secondary displacement due to inadequate fixation. 
Table 4: ANOVA analysis of time to union duration in different constructs.

\begin{tabular}{|llllllllll|} 
Weeks & N & Mean & SD & SE & \multicolumn{2}{l}{ 95\% confidence interval for mean } & Min & Max & P value \\
& & & & & Lower bound & Upper bound & & & \\
\cline { 1 - 1 } & 19 & 3.894 & 0.657 & 0.150 & 3.577 & 4.211 & 3 & 5 & \\
\hline $\mathbf{2}$ & 18 & 4.222 & 0.732 & 0.172 & 3.858 & 4.586 & 3 & 6 & \\
\hline $\mathbf{3}$ & 17 & 4.058 & 0.658 & 0.159 & 3.720 & 4.397 & 3 & 5 \\
\hline Total & 54 & 4.055 & 0.684 & 0.093 & 3.868 & 4.242 & 3 & 6 \\
\hline
\end{tabular}

Table 5: Cross tab analysis.

\begin{tabular}{|c|c|c|c|c|c|c|}
\hline \multirow{2}{*}{ Count } & \multirow{2}{*}{ Outcome } & \multirow{2}{*}{ Functional outcome Flynn } & \multicolumn{4}{|c|}{ Crosstabulation } \\
\hline & & & Excellent & Fair & Good & Total \\
\hline \multirow{4}{*}{ Cross K-wire } & \multirow{3}{*}{ Cosmetic outcome } & Excellent & 14 & 0 & 1 & 15 \\
\hline & & Fair & 0 & 0 & 1 & 1 \\
\hline & & Good & 1 & 1 & 1 & 3 \\
\hline & Total & & 15 & 1 & 3 & 19 \\
\hline \multirow{4}{*}{ Divergent LOP } & \multirow{3}{*}{ Cosmetic outcome } & Excellent & 13 & 0 & 1 & 14 \\
\hline & & Fair & 0 & 1 & 0 & 1 \\
\hline & & Good & 1 & 1 & 1 & 3 \\
\hline & Total & & 14 & 2 & 2 & 18 \\
\hline \multirow{2}{*}{ TOF-FCP } & \multirow{2}{*}{ Cosmetic outcome } & Excellent & 10 & & 4 & 14 \\
\hline & & Good & 2 & & 1 & 3 \\
\hline
\end{tabular}

They were revised with close reduction and percutaneous pinning. Both had fair functional outcome and cosmetic outcome was fair in one and good in the second. $5(27.8 \%)$ cases showed mild displacement, one (5.6\%) showed major displacement as per Skaggs criteria. Figure 3 shows radiographs and clinical photograph of a 4 years old child operated with lateral only pinning with excellent radiological and functional outcome.

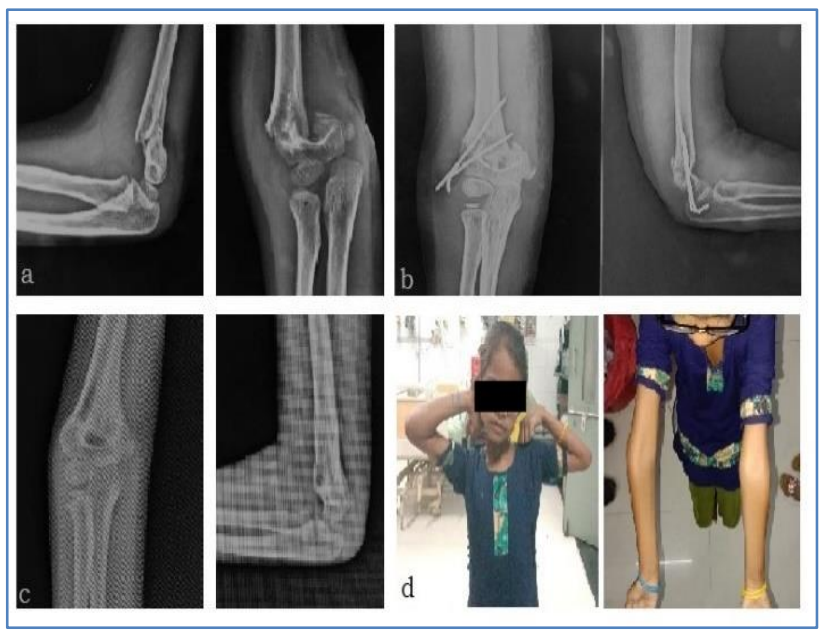

Figure 4: (a) Pre-operative radiograph of a fair outcome lateral only pinning case, (b) post loss of reduction radiograph of a fair outcome lateral only pinning case, (c) follow-up radiograph of a fair outcome lateral only pinning case and (d) clinical photograph of a fair outcome lateral only pinning case.
Figure 4 shows radiographs and clinical photograph of a 7 years old child operated with lateral only pinning with fair radiological and good functional outcome.

The average time to union in cross K-wire fixation was minimal i.e. 3.8 weeks, in TOF-FCP construct was 4 weeks and divergent lateral only pinning is 4.2 . weeks. ANOVA analysis has been carried out on this data which showed that the difference in the union time amongst them was not significant (Table 4).

Table 5 is the cross-tab analysis of all pinning methods' cosmetic and functional outcome. It shows that the cosmetic outcome is not necessarily related to the functional outcome. A fair (unsatisfactory) cosmetic outcome is associated with good (satisfactory) functional outcome.

Out of 19 cross pinned cases, no patient developed postoperative partial ulnar nerve injury following cross pinning. In the 35 lateral pinned cases no post-operative neurological loss was seen.

\section{DISCUSSION}

Functional outcome of cross pin fixation, in our study, $95 \%(79 \mathrm{E} ; 16 \mathrm{G})$ of cases had satisfactory outcome and $5 \%$ fair outcome. This is similar to the studies carried out previously where Flynn et al had 95\%, Sutton et al had $88 \%$, Mazda et al had 96\%, Prashant et al had $100 \%$ and Maity et al had $89 \%$ of satisfactory functional outcomes. ${ }^{6-10}$ 
For lateral pinning geometry, LOP (divergent) 89\% (78 E; $11 \mathrm{G}$ ) had excellent or good functional outcomes and $11 \%$ had fair outcome. Similarly, TOF-FCP configuration had $100 \%(71 \mathrm{E} ; 29 \mathrm{G})$ satisfactory outcome. This is similar to other studies where satisfactory outcome ranges from $85 \%$ to $100 \%$. Boyd et al had $95 \%$, Hadlow et al had $100 \%$, Mazda et al had $95 \%$ and Maity et al had $85 \%$ satisfactory functional outcome. ${ }^{11,12}$

A comparison of the functional outcome of the TOF-FCP method fixation in our study with that carried out by Kasirajan et al in 2017 showed similar functional outcome. $^{2}$ In our clinical study, out of 17 cases $100 \%$ showed excellent and good results which is similar to study by Kasirajan which had $96 \%$ satisfactory outcome.

Table 6: Comparison of cosmetic outcome with similar studies.

\begin{tabular}{|llll|}
\hline Procedure & Our study & $\begin{array}{l}\text { Maity } \\
\text { et al }^{10}\end{array}$ & $\begin{array}{l}\text { Prashant } \\
\text { et al }^{\mathbf{9}}\end{array}$ \\
\hline MLP & $3.8 \pm 3$ & $3.6 \pm 3$ & $3.8 \pm 2.02$ \\
\hline LOP divergent & $3.4 \pm 2.8$ & $3.9 \pm 3.3$ & $4.1 \pm 2.1$ \\
\hline TOF-FCP & $3.1 \pm 1.8$ & - & - \\
\hline
\end{tabular}

For cosmetic outcome the mean carrying angle in our study with its standard deviations was well within the range of the same obtained in other similar studies (Table 6). Also, there was minimal difference amongst them in the three different constructs which was not significant.

The advantage of medial-lateral pin fixation geometry is higher biomechanical stability, with iatrogenic ulnar nerve injury as its disadvantage. ${ }^{13-15}$ Conversely, the advantage of lateral entry pin fixation is avoidance of iatrogenic ulnar nerve injury, but the construct is less stable biomechanically. ${ }^{16}$ For this biomechanical study by Zionts et al, Skaggs et al and Chen et al demonstrated opposite outcomes. $^{13,17,18}$

The aim of operative treatment of displaced extension-type SCHF in children is achieving fracture reduction and fixation to get good functional and cosmetic outcome, while limiting neurovascular complications and deformities. Over the past decades, many studies concerning surgical treatment of SCHF have been published. Options for pin configuration include two/three lateral pins- divergent, two crossed pins, TOF-FCP. The TOF-FCP construct is a recently introduced construct which appears to have promising results but studies on its comparison with other constructs is lacking

Maity et al in their study came to the conclusion that the results between both the pinning techniques are same in terms of safety and efficacy. Prashant et al concluded that functional outcome of lateral only pinning (LOP) is similar to Medial-Lateral pinning (MLP) with the underlying risk of ulnar nerve injury in the latter. Mazda et al found that one technique was not superior to the other. Maity et al came to a similar conclusion. Thus, all of these studies found no significant difference between the two methods in terms of loss of reduction and found no significant difference between the two methods in terms of functional outcome. Only one showed a difference in favour of lateral pinning method in terms of iatrogenic nerve injury.

In our study results are consistent with the results of most of the previous studies with similar functional outcome in all three pinning methods without significant differences in outcome amongst them.

Furthermore, in our study in lateral only pinning, there are two configurations. One with a divergent configuration and one with a parallel configuration (TOF-FCP) with one of the entries with a capitellar entry point.

Gottschalk et al studies the two entry points in lateral only pinning in supracondylar humerus in their biomechanical study and found superiority in the capitellar entry pin. ${ }^{19}$ This was used in our TOF-FCP construct.

No cases of iatrogenic ulnar nerve injury were seen in our study. 3 cases of post-operative loss of reduction were seen in our study. Incidence of pin-tract infection were similar in all geometries in 3-4 range. Balakumar et al studied and reported the cause of loss of reduction in paediatric SCFH treated with percutaneous pinning. ${ }^{20}$ They reported loss of reduction in 14 out of 77 cases $(18.2 \%)$. Reduction was lost in 10 out of 29 children (34.5\%) who underwent lateral only pinning fixation and 4 out of $48(8.3 \%)$ children who had cross pinning fixation. They attributed the inadequate hold of pins or reduced spread of the pins.

In our study this was seen in 2 cases $(11.1 \%)$ in divergent LOP and 1 case $(5.3 \%)$ in cross pinning. In TOF-FCP construct in our study no case of loss of reduction was seen. The TOF-FCP fixation was stable enough to hold the fracture throughout the period of healing.

\section{CONCLUSION}

If a uniform standardized operative technique is followed in each method, then the result of all three percutaneous fixation methods will be same in terms of safety and efficacy. The selection of fixation method thus rests on the surgeon's preference and his confidence and familiarity with the method. The newer TOF-FCP does have lower rate of complications according to our study.

Funding: No funding sources

Conflict of interest: None declared

Ethical approval: The study was approved by the institutional ethics committee

\section{REFERENCES}

1. Farnsworth CL, Silva PD, Mubarak SJ. Etiology of supracondylar humerus fractures. J Pediatric Orthopaedics. 1998;18(1):38-42. 
2. Kasirajan S, Govindasamy R, Sathish BR, Meleppuram JJ. Trans-olecranon fossa four-cortex purchase lateral pinning in displaced supracondylar fracture of the humerus: a prospective analysis in 48 children. Revista Brasileira de Ortopedia (English Edition). 2018;53(3):342-9.

3. Gartland JJ. Management of supracondylar fractures of the humerus in children. Surg Gynecol Obstet. 1959;109(2):145-54.

4. Green DW, Widmann RF, Frank JS, Gardner MJ. Low incidence of ulnar nerve injury with crossed pin placement for pediatric supracondylar humerus fractures using a mini-open technique. J Orthop Trauma. 2005;19(3):158-63.

5. Aronson DD, Prager BI. Supracondylar fractures of the humerus in children. A modified technique for closed pinning. Clinical Orthopaedics Related Res. 1987;219:174-84.

6. Flynn JC, Matthews JG, Benoit RL. Blind Pinning of Displaced Supracondylar Fractures of the Humerus in Children: Sixteen Years' experience With LongTerm Follow-Up. JBJS. 1974;56(2):263-72.

7. Sutton WR, Greene WB, Georgopoulos GA, Dameron JT. Displaced supracondylar humeral fractures in children. A comparison of results and costs in patients treated by skeletal traction versus percutaneous pinning. Clinical Orthopaedics Related Res. 1992;278:81-7.

8. Mazda K, Boggione C, Fitoussi F, Pennecot GF. Systematic pinning of displaced extension-type supracondylar fractures of the humerus in children: a prospective study of 116 consecutive patients. J Bone Joint Surg Am. 2001;83(6):888-93.

9. Prashant K, Lakhotia D, Bhattacharyya TD, Mahanta AK, Ravoof A. A comparative study of two percutaneous pinning techniques (lateral vs mediallateral) for Gartland type III pediatric supracondylar fracture of the humerus. J Orthop Traumatol. 2016;17(3):223-9.

10. Maity A, Saha D, Roy DS. A prospective randomised, controlled clinical trial comparing medial and lateral entry pinning with lateral entry pinning for percutaneous fixation of displaced extension type supracondylar fractures of the humerus in children. J Orthop Surg Res. 2012;7(1):6.

11. Boyd DW, Aronson DD. Supracondylar fractures of the humerus: a prospective study of percutaneous pinning. J Pediatr Orthop. 1992;12(6):789-94.
12. Hadlow AT, Devane P, Nicol RO. A selective treatment approach to supracondylar fracture of the humerus in children. J Pediatr Orthop. 1996;16(1):104-6.

13. Zionts LE, McKellop HA, Hathaway R. Torsional strength of pin configurations used to fix supracondylar fractures of the humerus in children. $\mathbf{J}$ Bone Joint Surg Am. 1994;76(2):253-6.

14. Lee SS, Mahar AT, Miesen D, Newton PO. Displaced pediatric supracondylar humerus fractures: biomechanical analysis of percutaneous pinning techniques. J Pediatr Orthop. 2002;22(4):440-3.

15. Brauer CA, Lee BM, Bae DS, Waters PM, Kocher MS. A systematic review of medial and lateral entry pinning versus lateral entry pinning for supracondylar fractures of the humerus. J Pediatr Orthop. 2007;27(2):181-6.

16. Sibinski M, Sharma H, Sherlock DA. Lateral versus crossed wire fixation for displaced extension supracondylar humeral fractures in children. Injury. 2006;37(10):961-5.

17. Omid R, Choi PD, Skaggs DL. Supracondylar humeral fractures in children. J Bone Joint Surg Am. 2008;90(05):1121-32.

18. Chen TL, He CQ, Zheng TQ, Gan YQ, Huang MX, Zheng YD, et al. Stiffness of various pin configurations for pediatric supracondylar humeral fracture: a systematic review on biomechanical studies. J Pediatr Orthop B. 2015;24(5):389-99.

19. Gottschalk HP, Sagoo D, Glaser D, Doan J, Edmonds EW, Schlechter J. Biomechanical analysis of pin placement for pediatric supracondylar humerus fractures: does starting point, pin size, and number matter. J Pediatr Orthop. 2012;32(5):445-51.

20. Balakumar BVM. A retrospective analysis of loss of reduction in operated supracondylar humerus fractures. Indian J Orthop. 2012;46(6):690.

Cite this article as: Shah SB, Parikh KN, Paraliya PI. A study on outcome of various K-wire fixations in paediatric supracondylar humerus fractures. Int $\mathbf{J}$ Res Orthop 2020;6:896-901. 